\title{
Directions of development of research methods in the assessment of leaching of heavy metals from mineral waste
}

\author{
Anna Król ${ }^{1, a}$ and Kamila Mizerna ${ }^{1}$ \\ ${ }^{1}$ Opole University of Technology, Department of Environmental Engineering, 5 Mikołajczyka Street, 45-271 Opole, Poland
}

\begin{abstract}
There are many test methods to assess the level of the release of heavy metals into the environment from mineral waste materials. Leaching methods can be different depending on the leaching time periods, leaching dynamics, sample preparation method or the $\mathrm{pH}$ of the elution medium. In Poland, little attention is paid to the research on the relationship between the leaching of particular heavy metals from mineral wastes and changes in environmental conditions, including the $\mathrm{pH}$ of the environment. Tests being carried out abroad have started to pay great attention to the $\mathrm{pH}$-dependent impact of the environment and the liquid being in contact with the material on the degree of leaching contaminants from wastes. The solubility of all metals depends on the value of the $\mathrm{pH}$. Authors of the paper will try to prove that Polish methods of waste characterization is incomplete and inconsistent with opinions prevailing in the global literature. The procedure described in the Polish standards are insufficient to determine the actual level of leaching of heavy metals having regard to the impact of multiple external conditions on the level of leaching of heavy metals. Paper will present a directions of development of research methods in the assessment of leaching of heavy metals from mineral waste.
\end{abstract}

\section{Introduction}

Improper management of industrial wastes can impact all components of the environment. Mineral wastes from mining, power and metallurgy industry are characterized by varying properties and the level of contamination caused by heavy metals, depending on the source and technology being used. The knowledge of the content and chemical properties of wastes determines the way in which they are managed. The most desirable direction is the recycling by entering the waste for the second time into technological cycle or for its re-use by other industrial sectors. However, not all waste can be utilized in such a way or such action can be economically unviable. Therefore, wastes are being subjected to temporal deposition in heap or in landfills, although it is an ultimate and least preferred direction in the waste management [1].

Wastes placed in the natural environment are exposed to a variety of physical, biological and chemical factors having an impact on the level of the release of heavy metals. Climatic conditions occurring in a landfills or in a heaps, especially the amount of precipitation have a significant impact on the volume of water, which is infiltrating through the mass of waste being deposited in landfills. Water is an agent facilitating implementation of a variety of chemical processes. It aids in the dissolution and leaching of contaminants from wastes, which in turn can lead to contamination of soil and water environment. The main factors, which influence the process of leaching of heavy metals are: fragmentation and shape of the waste, the ambient temperature, the ratio of liquid to solid (L/S ratio), redox potential and contact time with rainwater [2, 3]. One of the key parameters governing the leaching process is also the $\mathrm{pH}$ level of the environment in which the waste is located [4]. Significant decrease in the $\mathrm{pH}$ of the eluent can lead to the situation that the leaching process can be accompanied by solubilisation of wastes, which can widely promote changes in the levels of the release of heavy metals from great amounts of wastes.

Research of heavy metals leaching under the impact of environmental factors is possible by using various leaching tests. Performing leaching tests by taking into account the impact of atmospheric conditions or simulation of such conditions in the laboratory is one of the objectives for a comprehensive and correct assessment of the level of leaching heavy metals from various materials having contact with the natural environment [5]. Worldwide there are applied different leaching test methods. These methods can be divided according to the leaching time periods, leaching dynamics, sample preparation method or the $\mathrm{pH}$ of the elution medium. Subject of this paper was undertaken due to the fact that in the legislation being in force in Poland, the explicit standard regarding waste characterization concerning the leaching of heavy metals is PN-EN 12457:2006 [6]. However, the procedure described in the standard is insufficient to determine

\footnotetext{
a Corresponding author: a.krol@po.opole.pl
} 
the actual level of leaching of heavy metals having regard to the impact of multiple external conditions on the release of heavy metals.

\section{The current state of knowledge}

In the last two decades, research on the assessment of leaching behaviour of particular heavy metals from various types of materials (including construction mineral materials, granular materials and wastes) were undertaken. H. A. van der Sloot [5, 7-9] has contributed to expand the knowledge about factors and processes determining the leaching of heavy metals mainly from mineral construction materials in different exposure conditions. Due to the fact that wastes, similar as mineral materials, after being places in the natural environment are exposed to contact with its various components (soils, surface water, air), these factors can also affect the leaching of contaminants from such kind of materials.

In worldwide research have started to pay great attention to the $\mathrm{pH}-$ dependent impact of the environment and the liquid being in contact with the material on the level of leaching contaminants from wastes $[3,4,8,9-13,14-16]$. The solubility of all metals depends on the value of the $\mathrm{pH}$ [17]. The common view being described in the literature is that cations of $(\mathrm{Ni}, \mathrm{Cu}$, $\mathrm{Zn}, \mathrm{Cd}, \mathrm{Pb}, \mathrm{Al}, \mathrm{Fe}$ ) are characterized by the highest rate of the release in an acidic environment and anions of ( $\mathrm{Cr}, \mathrm{Mo}, \mathrm{As}, \mathrm{Se}, \mathrm{Sb})$ in the basic environment (Fig. 1). However, the tendencies of changes in the leaching of heavy metals as a function of the $\mathrm{pH}$ can vary depending on the type and level of contamination of the test material and its physico-chemical characteristics.
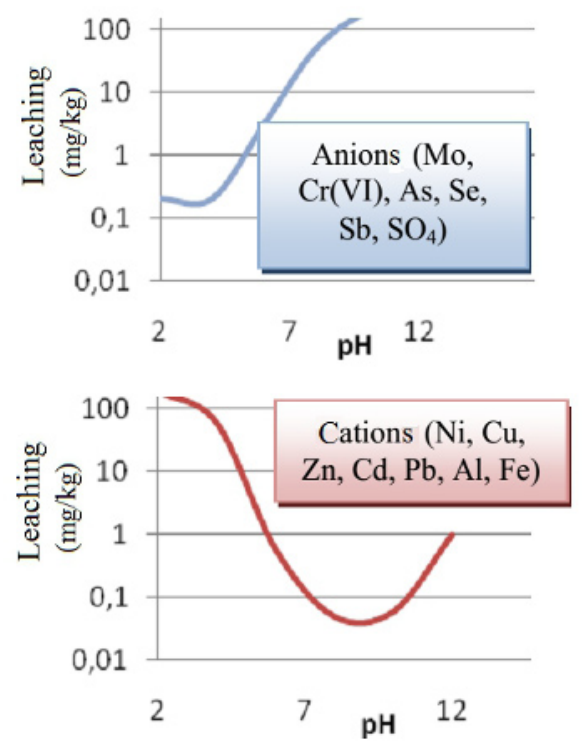

Figure 1. The $\mathrm{pH}$ - dependent leaching of anions and cations of heavy metals [8].

In the literature $[9,11,13]$ the results of leaching zinc, lead, nickel and also copper [12] as a function of the $\mathrm{pH}$ are presented in the form of conventional „U” or ,V” shaped curves, being obtained in the $\mathrm{pH}$ dependence tests
$[18,19]$. With these methods consisting on constant adding for 48 hours an acid or alkali in order to maintain the desired $\mathrm{pH}$ value, there are observed trends in the behaviour of leaching contaminants depending on changes in the $\mathrm{pH}$ of the environment in which the waste is placed. Leaching tests of heavy metals from various waste materials conducted by van der Sloot [9] and Vitková [13] show that the highest concentrations of zinc, nickel and lead are being obtained in an extremely acidic environment and the lowest ones at $\mathrm{pH}$ ranging from 7 to 10 , depending on the test material. In the basic medium, another increase in concentrations of the above mentioned heavy metals is being observed. For cooper, the leaching curve does not always adopts the shape of „U” letter. In the research by van der Sloot [9] there are observed downward as well as upward trends in the level of leaching of this element as the eluent's pH increases. This is caused by various capacities to neutralize acid or alkali by the test material. Tests performed by van der Sloot [9] also indicate the leaching tends of chromium, the concentrations of which are the highest in a strongly alkaline environment.

In Poland, little attention is paid to the research on the relationship between the leaching of particular heavy metals from mineral wastes and changes in environmental conditions. Therefore, the problem of the impact of environmental factors on the leachability of heavy metals from wastes was undertaken by the authors of the paper. Authors have a results of preliminary research on the release of heavy metals from industrial wastes [20-22], which indicate the need for drawing attention in the leaching process on factors such as: particle size of the waste and the $\mathrm{pH}$ of the eluent (elution medium). Król [23-25] has also carried out the research on the impact of temperature change and acting of chemically aggressive fluids on the level of the release of heavy metals from mineral composites containing solidified hazardous wastes. The research unambiguously indicates the meaning of changing conditions of conducting the process on the level of heavy metal release, and thus the fact of how important is the carrying out the leaching tests using various methods.

\section{Tests for leaching of heavy metals from mineral wastes}

The need to develop complex methods for waste characterization and assessment of the release of heavy metals was observed in the 90 s of the twentieth century [15]. Leaching tests have proven to be an indispensable tools to evaluate the behaviour of release of hazardous substances to the environment from different types of materials under natural conditions and under the impact of external factors. The European Committee for Standardization (CEN) has been a pioneer in the creation of a unified draft of the new leaching tests partly based on the already used procedures. The Dutch Standards Institute (NEN) has also contributed to development of leaching methods. Research of heavy 
metals leaching from mineral wastes using several different tests allows us to characterize the waste in a broader range and evaluate the behaviour of the heavy metals release in different environmental conditions.

Methods of heavy metals leaching can be divided according to:

- leaching time periods:

- long-term - test examples: tank test [26], column test [27]

- short-term - test examples: batch test [6], maximum availability leaching test [28];

- leaching dynamics:

- static - the quantity of the sample solution is specified and joined by a fixed period of time [16]; product of this connection is the leached substance (eluate); test examples: tank test [25], $\mathrm{pH}$ dependence tests [18, 19], batch test [6]

- dynamic - the substance resulting in leaching constantly flows through the sample; test example: column test [27];

- sample preparation method - the sample can be: monolithic, cut off from a monolith and fragmented; the monolithic samples mean integrated samples. In the tank test [26], monolithic samples are used that are placed for a specified period of time in containers with liquid (demineralized water). While, in the batch test [6] a fragmented sample with grain size of less than 4 $\mathrm{mm}$ or $10 \mathrm{~mm}$ and with a mass of $100 \mathrm{~g}$ is being poured with an appropriate amount of water (the ratio of the liquid phase to the solid phase is $\mathrm{L} / \mathrm{S}=10$ or 2 ) and agitated for 24 hours. The eluent is here in contact with a large surface area of the particulate waste material. Column tests in which the material is fragmented to a grain size of $<4 \mathrm{~mm}$ is packed in a column are utilizing the percolation process for leaching heavy metals from waste materials [27];

- the $\mathrm{pH}$ of the elution medium - neutral, acidic or alkaline. In the tank test [26] is used a liquid (demineralized water) having a neutral $\mathrm{pH}$, which covers the monolithic sample. While, in the procedure $\mathrm{pH}$ dependence tests $[18,19]$, the test sample is subjected to the impact of the liquid having various $\mathrm{pH}$ levels (the $\mathrm{pH}$ from 4 to 12 ).

When selecting the research methods for assessment the level of leaching, the form in which the test material is deposited is a very important issue. This relates to various processes being accompanied by the heavy metal release from the waste materials. For waste in monolithic forms this phenomenon is an effect of diffusion or dissolution processes imposed by the leaching from the surface [26]. Conditions for performing the research should consider various factors that influence the behaviour of particular heavy metals. The ongoing structural changes caused by external factors (temperature changes, changes in the $\mathrm{pH}$, water contact) can lead to an increase in level of heavy metals being released from materials into the natural environment [5]. The processes as oxidation, carbonation and other corrosive effects of aggressive media entail the need of understanding the impact of particular factors on the phenomenon of leaching heavy metals, considering the entire "life cycle" of the test material. Therefore, the research study on the impact of various factors on the release of heavy metals from wastes will be performed by using a number of leaching tests or their modifications. The different methods of heavy metals leaching from various waste materials are presented in Table 1.

The $\mathrm{pH}$ dependence tests are used in order to assess the impact of a wide range of $\mathrm{pH}$ on the leaching process of heavy metals release. Tests consist in maintaining

Table 1. Comparison of leaching tests.

\begin{tabular}{|c|c|c|c|c|c|c|c|c|c|}
\hline \multicolumn{2}{|c|}{ Leaching test } & $\begin{array}{c}\text { Test } \\
\text { category }\end{array}$ & $\begin{array}{l}\text { Type of } \\
\text { waste } \\
\text { material }\end{array}$ & $\begin{array}{c}\text { Sample } \\
\text { particle size }\end{array}$ & $\begin{array}{c}\text { Dry mass } \\
\text { or volume } \\
\text { of the } \\
\text { sample } \\
\end{array}$ & $\begin{array}{l}\mathrm{pH} \text { of } \\
\text { the } \\
\text { eluent }\end{array}$ & L/S ratio & $\begin{array}{l}\text { Procedure } \\
\text { duration }\end{array}$ & $\begin{array}{l}\text { Mixing/ } \\
\text { s haking }\end{array}$ \\
\hline \multirow{4}{*}{$\begin{array}{l}\text { Batch } \\
\text { test [6] }\end{array}$} & Part 1 & \multirow{4}{*}{ static test } & \multirow{4}{*}{$\begin{array}{l}\text { all waste } \\
\text { materials } \\
\text { (granular) }\end{array}$} & \multirow{3}{*}{$<4 \mathrm{~mm}$} & $175 \pm 5 \mathrm{~g}$ & \multirow{4}{*}{$5 \div 7,5$} & $2 \mathrm{dm}^{3} / \mathrm{kg}$ & $24 \mathrm{~h}$ & \multirow{4}{*}{ yes } \\
\hline & Part 2 & & & & $90 \pm 5 \mathrm{~g}$ & & $10 \mathrm{dm}^{3} / \mathrm{kg}$ & $24 \mathrm{~h}$ & \\
\hline & Part 3 & & & & $175 \pm 5 g$ & & $\begin{array}{l}2 \text { and } 8 \\
\mathrm{dm}^{3} / \mathrm{kg}\end{array}$ & $6 \mathrm{~h}+18 \mathrm{~h}$ & \\
\hline & Part 4 & & & $<10 \mathrm{~mm}$ & $90 \pm 5 \mathrm{~g}$ & & $10 \mathrm{dm}^{3} / \mathrm{kg}$ & $24 \mathrm{~h}$ & \\
\hline \multicolumn{2}{|c|}{$\begin{array}{l}\text { pH dependence } \\
\text { tests }[18,19]\end{array}$} & static test & $\begin{array}{l}\text { all waste } \\
\text { materials } \\
\text { (granular) }\end{array}$ & $<1 \mathrm{~mm}$ & $\begin{array}{c}15,30 \text { or } 60 \\
\mathrm{~g} \pm 10 \%\end{array}$ & $\begin{array}{l}\text { target } \\
4 \div 12\end{array}$ & $10 \mathrm{dm}^{3} / \mathrm{kg}$ & $48 \mathrm{~h}$ & yes \\
\hline \multicolumn{2}{|c|}{$\begin{array}{c}\text { Maximum } \\
\text { availability } \\
\text { leaching test [28] }\end{array}$} & static test & $\begin{array}{l}\text { all waste } \\
\text { materials } \\
\text { (granular) }\end{array}$ & $<0.125 \mathrm{~mm}$ & $16 \pm 2 \mathrm{~g}$ & $\begin{array}{l}\text { target } \\
7 \text { and } 4\end{array}$ & $50 \mathrm{dm}^{3} / \mathrm{kg}$ & $6 \mathrm{~h}$ & yes \\
\hline \multicolumn{2}{|c|}{ Tank test [26] } & static test & $\begin{array}{l}\text { all waste } \\
\text { materials } \\
\text { (moulded or } \\
\text { monolithic) }\end{array}$ & $\begin{array}{c}\text { one sample } \\
\text { dimension } \\
\text { of at least } 40 \\
\mathrm{~mm} \\
\end{array}$ & $\begin{array}{c}\text { not } \\
\text { applicable }\end{array}$ & $5 \div 7,5$ & $\begin{array}{c}\text { not } \\
\text { applicable }\end{array}$ & 64 days & no \\
\hline \multicolumn{2}{|c|}{$\begin{array}{c}\text { Dynamic } \\
\text { monolithic } \\
\text { leaching test [29] }\end{array}$} & $\begin{array}{l}\text { dynamic } \\
\text { test }\end{array}$ & $\begin{array}{l}\text { all waste } \\
\text { materials } \\
\text { (moulded or } \\
\text { monolithic) }\end{array}$ & $\begin{array}{c}\text { one sample } \\
\text { dimension } \\
\text { of at least } 40 \\
\mathrm{~mm}\end{array}$ & $\begin{array}{c}\text { not } \\
\text { applicable }\end{array}$ & $5 \div 7,5$ & $\begin{array}{c}\text { not } \\
\text { applicable }\end{array}$ & 36 days & no \\
\hline \multicolumn{2}{|c|}{ Column test [27] } & $\begin{array}{l}\text { dynamic } \\
\text { test }\end{array}$ & $\begin{array}{l}\text { all waste } \\
\text { materials } \\
\text { (granular) }\end{array}$ & $\begin{array}{c}<4 \text { or }<10 \\
\mathrm{~mm}\end{array}$ & $\begin{array}{c}0,6 \text { or } 2,4 \\
\mathrm{dm}^{3} \text { after } \\
\text { compaction } \\
\end{array}$ & $\begin{array}{l}\text { approx. } \\
7\end{array}$ & $10 \mathrm{dm}^{3} / \mathrm{kg}$ & $\begin{array}{l}\text { approx. } 30 \\
\text { days }\end{array}$ & no \\
\hline
\end{tabular}


constant $\mathrm{pH}$ level of the eluent for a predetermined period of time (with the target for 48 hours), and thereby, to assess the release of inorganic components from the waste in an extremely acidic and basic conditions. The test involves reaching the equilibrium condition between the test material and the eluent. This condition is reached when pre-determined (computed) amount of acid or base (standard EN 14429:2015 [19]) is being added to the water, in order to achieve and maintain the desired $\mathrm{pH}$ value at constant level or the value is continuously monitored and controlled by adding automatically an acid or a base (standard EN 14997:2015 [18]). The standards apply to all types of waste materials (with the grain size of $<1 \mathrm{~mm}$ ). The test will cover eight selected values of $\mathrm{pH}$ ranging from 4 to 12 (the range can be expanded if necessary). The $\mathrm{pH}$ values are being measured after 4, 44 hours and after 48 hours from the time of pouring the sample with eluent. The capacity of waste to neutralize acid (ANC) or base (BNC) can be determined in the discussed tests. This property is obtained based on the amount of acid or base being added to achieve the final predetermined $\mathrm{pH}$ level $[18,19]$.

The maximum availability leaching test allows researchers to assess the leaching behaviour of contaminants by using liquid with the $\mathrm{pH}$ level of 7 and 4 . Based on the results, the capability to neutralize acid by wastes at a given $\mathrm{pH}$ can be also determined. The test is applied to determine leaching of inorganic components, which can be leached from fine-grained waste materials exposed to extreme weather conditions or being after the dissolution of the material or in the case of loss of the capacity for neutralization of acids. The availability test is a two-step analysis performed from the moment of reaching by the eluate the $\mathrm{pH}$ at the level of 7 in the first stage and at the level of 4 during the second stage. At least $95 \%$ of dry weight of the sample should be of particles with the size smaller than $125 \mu \mathrm{m}$. The aqueous extract is obtained from $16 \mathrm{~g}$ of such fragmented material. The material is mixed with water for a total of 6 hours by using a stirrer in the ratio of $\mathrm{L} / \mathrm{S}=50 \mathrm{dm}^{3} / \mathrm{kg}$. By using the $\mathrm{pH}-$ meter, the $\mathrm{pH}$ level of the eluate should be measured after one and ten minutes from the moment of agitation. This is used for classification of the test material (in terms of acid or alkaline reagent). Based on this classification, the concentration of nitric acid being added to lower the $\mathrm{pH}$ of the eluate is being determined. Extracts obtained during the two stages were mixed together and analysed according to the content of selected impurities [28].

Assessment of processes accompanying the leaching of heavy metals from waste materials and the impact of time during which the liquid is in contact with the sample on the leachability will be carried out in the tank test or dynamic monolithic leaching test (DMLT). Procedure of both tests is similar. The difference is due to the duration of the tests. DMLT lasts 36 days and tank test lasts 64 days. Waste in a monolithic form (minimum size of one sample dimension $=40 \mathrm{~mm}$ ) is subjected to leaching in a closed tank. The sample with known surface area and volume is poured with distilled, so the volume of the liquid will be $2 \div 5$ times greater than the volume of the sample (in the tank test) or 8 times greater than the surface of the sample (in DMLT). The distance of all surface areas of the sample from walls of the tank should be at least 2centimeter long. Eluates are collected in the 8 test periods. After each collection of the eluate, the liquid is being exchanged in its entirety and then a sample is fixed inside again. Subsequently, after the eluates filtration, the $\mathrm{pH}$ level is measured and the concentration of heavy metals is determined for each eluate fraction ( 8 fractions). For each of the analysed heavy metal, following can be determined during the research tests: the leachability in the eluate fraction, the total leaching per unit surface area and emerging leaching processes (diffusion, elution from surface area, depletion, dissolution, delayed diffusion or dissolution) [26, 29].

By performing column tests it is possible to assess the leaching of heavy metals in certain percolation conditions that are dynamic conditions. Wastes can contain unstable substances, which are decomposed under the influence of weather conditions, and this causes the release of additional pollution loads. Therefore, dynamic tests simulate real conditions of the leaching of contaminants in the landfill aeration zone. Column test also allows researchers to perform the observations on how the change of the liquid to solid $(\mathrm{L} / \mathrm{S})$ ratio influences the obtained concentrations of particular components. The test material is being packed in a column of a suitable size. On the applied size of the column (with diameter of $5 \mathrm{~cm}$ or $10 \mathrm{~cm}$ ) decides the waste particle size. The column packed with waste is being weighed and then the material is saturated. The saturated material is left for three days to stabilize the system. Then, the distilled water is provided to the column, which flow upwards the column with a determined flow rate until reach the eluate with predetermined liquid to solid ratio $(\mathrm{L} / \mathrm{S}=0.1 ; 0.2 ; 0.5$; $1.0 ; 2.0 ; 5.0 ; 10.0 \mathrm{dm}^{3} / \mathrm{kg}$ ). In this manner, seven eluates are derived, which are after filtration subject to the analysis on the content of heavy metals [27].

The batch test is relatively quick and often used procedure. The scheme of batch test procedure was presented in Figure 2. Test should be carried out according to the part 1 of standard [6]: PN-EN 124571:2006 (single batch test at $\mathrm{L} / \mathrm{S}=2 \mathrm{dm}^{3} / \mathrm{kg}$ ), part 2: PNEN 12457-2:2006 (single batch test at $\mathrm{L} / \mathrm{S}=10 \mathrm{dm}^{3} / \mathrm{kg}$ ), part 3: PN-EN 12457-3:2006 (two stage batch test at L/S $=2$ and $8 \mathrm{dm}^{3} / \mathrm{kg}$ ) or part 4: PN-EN 12457-4:2006 (single batch test at $\mathrm{L} / \mathrm{S}=10 \mathrm{dm}^{3} / \mathrm{kg}$ ). Particulate material with relevant grain size of $<4 \mathrm{~mm}$ or $<10 \mathrm{~mm}$ is subject of agitation with water for 24 hours. Shaker's rotations should be set on in such a way to prevent deposition of solid particulates. After the shaking process ends, the containers should be left for about 15 minutes, so the process of sedimentation of solid particles take place. Subsequently, the eluate is being filtered through membrane filter and analysed. In the legislation being in force in Poland, the explicit standard regarding waste characterization concerning the leaching of heavy metals is PN-EN 12457:2006 [6]. The requirement for the waste to be deposited in a designated type of a landfill (inert, hazardous or non-hazardous) is fulfilling relevant 
criteria on the leaching of contaminants. However, the batch test doesn't include the conditions and their changes occurring during waste deposition in the environment (heaps, landfills). On the basis of own preliminary tests [22] in accordance with the

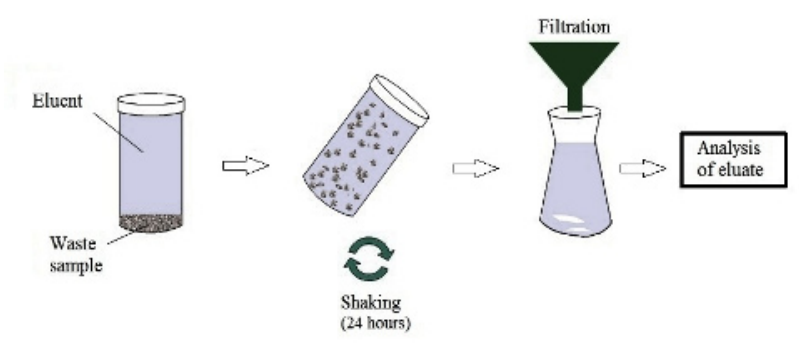

Figure 2. Scheme of batch test according to PN-EN 12457:2006 [6].

abovementioned standard, it was noted that if a little change decreasing or increasing the $\mathrm{pH}$ level of the eluent influences the release of varying amounts of heavy metals. Therefore, a change in the $\mathrm{pH}$ environment, for example as a result of acting rainwaters or leaching the waste in the deposited mass, can cause an increase in the level of the release of contaminants from wastes. This is important when classifying the waste or when determining the capacity of its deposition in landfills of a given type. In Poland, wastes are classified based on leachability criteria set out in the Regulation of the Ministry of Economy of 16 July 2015 on the acceptance of waste for landfill [30]. Due to various impacts affecting the waste being deposited in a landfill for inert wastes, the limit values for the leaching of heavy metals determined for such type of landfills can be exceeded. Then, it can turn out that the waste should be deposited in hazardous waste landfills.

\section{Conclusions}

Development of different research methods in assessment of heavy metals leaching from mineral waste was an important step towards the development of waste studies. Research of release of heavy metals from waste by several leaching methods allow us to assess the leaching behaviour in different waste exposure conditions. It is also possible the proper determination and prediction of heavy metals leaching taking into account the impact of many factors and processes (the $\mathrm{pH}$ of environment, amount of rainwater, landfilling duration). Complex testing methods of leaching of heavy metals from mineral waste make it possible to assess the short- and long-term effects of leaching. Authors in the paper sought to indicate the relevant methods and tests allowing a comprehensive assessment of mineral industrial wastes in terms of the release of heavy metals. Both the structure, type and method of potential waste management decide on the method to assessment the process of leaching of contaminants. Using a various tests can assess how the waste is hazardous and which risks to the environment. This allows us to choose the appropriate direction of development of waste. It therefore seems that the adopted in Poland leaching methods and thereby the aggregation of the research results connected with databases on waste categorization into particular groups (neutral, hazardous) provides incomplete image on the state of risk, which is posed by waste deposited in the environment in terms of the release of heavy metals.

\section{References}

1. Polish Act on Waste of 14 December 2012 on Poland's Journal of Laws dated January 8, 2013, item

21,http://isap.sejm.gov.pl/DetailsServlet?id=WDU201 30000021

2. A. Król, Arch. Civ. Eng. Environ. 4, 3, 71-76 (2011), http://acee-journal.pl/1,7,20,Issues.html

3. H.A van der Sloot, A. van Zomeren, Mine Water Environ. 31, 92-103 (2012), doi: 10.1007/s10230012-0182-8

4. M. Vitková, V. Ettler, O. Šebek, M. Mihaljevič, T. Grygar, J. Rohovec, J. Hazard. Mater. 167, 427-433 (2009), doi: 10.1016/j.jhazmat.2008.12.136

5. H.A van der Sloot, A. van Zomeren, J.C.L Meeussen., P. Seignette, R. Bleijerveld, J. Hazard. Mater. 141, 2, 354-369 (2007), DOI: 10.1016/j.jhazmat.2006.05.106

6. PN-EN 12457:2006. Characterisation of waste. Leaching. Compliance test for leaching of granular waste materials and sludges. Part 1-4

7. H.A van der Sloot, J. Dijkstra, Development of horizontally standardized leaching tests for construction materials: a material based or release based approach? Report ECN-C-04-060 (2004)

8. H.A van der Sloot, J. Dijkstra, P. Seignette, O. Hjelmar, G. Spanka, Characterisation leaching tests as basis of reference for quality control and decisions on acceptability of alternative materials in construction, Energy Research Centre of the Netherlands, Wascon Conference, Lyon (2009)

9. H.A van der Sloot, Horizontal standardization and harmonization of leaching test methods for waste, secondary raw materials, construction materials and (contaminated) soil, Proceedings of the Wascon Conference, San Sebastian (2003), https://www.ecn.nl/docs/society/leaching/wascon_005 .pdf

10.M.J. Quina, J.C.M. Bordado, R.M. Quinta-Ferreira, The influence of $\mathrm{pH}$ on the leaching behaviour of inorganic components from municipal solid waste APC residues, Waste Manage. 29, 2483-2493 (2009), doi: 10.1016/j.wasman.2009.05.012

11.D. Centioli, R.N.J. Comans, S. Gaudino, C. Galas, M. Belli, Ann. Ist. Super. Sanita 44, 3, 252-257 (2008), http://www.iss.it/binary/publ/cont/252\%20\%20ANN_08_36\%20Centioli.1224497272.pdf

12. V. Cappuynus, R. Swennen, J. Hazard. Mater. 158, 1, 185-195 (2008), doi: 10.1016/j.jhazmat.2008.01.058

13. M. Vitková, V. Ettler, O. Šebek, M. Mihaljevič, Mineral. Mag. 72, 1, 521-524 (2008), doi: 10.1180/minmag.2008.072.1.521 
14.J. Yao, W.B. Li, Q. Kong, F. Xia, D.S. Shen, Fuel, 93, 99-104 (2012), doi: 10.1016/j.fuel.2011.11.026

15. J.L.T Hage, E. Mulder, Waste Manage. 24, 2, 165172 (2004), doi: 10.1016/S0956-053X(03)00129-6

16. J. Kalembkiewicz, E. Sitarz-Palczak, J. Ecol. Eng. 16, 1, 67-80 (2015), doi: 10.12911/22998993/589

17. N. Rothe, K.O Gundermann, F. Jentsch, Zentralbl. Bakteriol. Mikrobiol. Hyg. B. 187, 2, 112-124 (1988)

18. EN 14997:2015 Characterization of waste. Leaching behaviour test. Influence of $\mathrm{pH}$ on leaching with continuous $\mathrm{pH}$ control.

19.EN 14429:2015 Characterization of waste. Leaching behaviour test. Influence of $\mathrm{pH}$ on leaching with initial acid/base addition.

20. K. Mizerna, A. Król, Inż. Ekolog. 43, 1-6 (2015) (in Polish), doi: $10.12912 / 23920629 / 58898$

21. A. Król, K. Mizerna, Chemik, 69, 10, 670-673 (2015), http:/www.chemikinternational.com/wpcontent/uploads/2015/10/10_15-ro\%CC\%811_GB.pdf

22. K. Mizerna, A. Król, Appl. Mech. Mat. 797, 408-414 (2015), doi:10.4028/www.scientific.net/AMM.797

23. B. Augustyniok, D. Jagoda, A. Król, R. RoszczykWalczak, Release of heavy metals from concrete as a result of impact of high temperature, Proceedings of ECOpole, 1, 1/2, 81-84 (2007) (in Polish). http://tchie.uni.opole.pl/ecoproc07/Augustyniok_07.p df

24. A. Kró1, Z. Giergiczny, J. Hazard. Mater. 160, 2-3, 247-255 (2008), doi: 10.1016/j.jhazmat.2008.03.007

25. A. Król, Environ. Prot. Eng. 38, 4, 29-40 (2012), doi: $10.5277 / \mathrm{EPE} 120403$

26.EA NEN 7375:2004 Leaching characteristics of moulded or monolithic building and waste materials. Determination of leaching of inorganic components with the diffusion test. The Tank Test

27. CEN/TS 14405:2004 Characterization of waste. Leaching behaviour tests. Up-flow percolation test

28.EA NEN 7371:2004 Leaching characteristics of granular building and waste materials. The determination of the availability of inorganic components for leaching. The maximum availability leaching test

29. EN 15863:2015 Characterization of waste. Leaching behaviour test for basic characterization. Dynamic monolithic leaching test with periodic leachant renewal, under fixed test conditions

30. Regulation of the Ministry of Economy of 16 July 2015 on the acceptance of waste for landfill, Poland's Journal of Laws dated September 1, 2015, item 1277 